\title{
Topical Delivery of Levocarnitine to the Cornea and Anterior Eye by Thermosensitive in-situ Gel for Dry Eye Disease
}

\section{Baorui Ma* \\ Linnuo Pang* \\ Pingqing Huang \\ Jie Bai \\ Zhiqin Zhang \\ Huimin Wu \\ Mengru Cai \\ Jin Yang \\ Yuchen Xu \\ Xingbin Yin (D) \\ Changhai Qu \\ Jian $\mathrm{Ni}$}

School of Chinese Materia Medica, Beijing University of Chinese Medicine, Beijing,

People's Republic of China

*These authors contributed equally to this work

\begin{abstract}
Purpose: To prepare the levocarnitine thermosensitive in situ gel (LCTG) and evaluate its effect on dry eye disease (DED).

Methods: Draize eye irritation test and other examinations were used to evaluate the eye irritation after multiple administration of LCTG. The Schirmer test, fluorescein sodium staining, HE staining and TUNEL staining were used to detect the tear secretion, corneal injury, histopathological changes of the cornea and lacrimal gland, and the apoptosis rate of cornea epithelial cells after 3 days of the administration. The conjunctival goblet cell density was detected by PAS staining, and the expression levels of matrix metalloproteinase-3 (MMP-3) and matrix metalloproteinase-9 (MMP-9) of corneal epithelial cells were detected by immunofluorescence staining after 7 days of the administration.

Results: LCTG is non-irritating to rabbit eyes and has good biocompatibility. LCTG administration for 3 days can significantly increase the amount of tear secretion in mice with DED, promote corneal epithelial integrity and central corneal epithelium thickness recovery, and improve the pathological morphology and structure of corneal and lacrimal gland tissues, and reduce the apoptosis rate of the corneal epithelial cells. After 7 days of the administration, the preparation can promote the proliferation of conjunctival goblet cells and down-regulate the cornea expression levels of MMP-3 and MMP-9 in epithelial cells.
\end{abstract}

Conclusion: The LCTG has a good curative effect on mice with DED, and the overall curative effect is better than that of levocarnitine solution.

Keywords: levocarnitine, cornea, in situ gel, delivery, dry eye disease

\section{Introduction}

The eye is one of the most delicate organs in the human body with unique anatomical and physiological characteristics. In recent years, the new lifestyles driven by information technology have caused the increased incidence of eye diseases year by year. ${ }^{1}$ DED (Dry Eye Diseases) is one of the most common ocular surface diseases in the world and the pooled prevalence of DED in China was $17.0 \%{ }^{2}$ DED is multifactorial disorder of the ocular surface and patients are usually plagued by symptoms such as decreased tear production, photophobia, asthenopia and irritation. ${ }^{3-5}$ And the main harm caused by severe DED is the apoptosis of corneal epithelial cells, repeated inflammation and the occurrence of the corneal basal immune cascade which affects the integrity and transparency of the cornea, causing severe eye pain, blurred vision and even blindness. ${ }^{6}$ The results of DED pathophysiological studies have shown that hypertonicity, inflammation
Correspondence: Changhai Qu; Jian Ni School of Chinese Materia Medica, Beijing University of Chinese Medicine, Higher Education Zone, Fangshan District, Beijing, 102488, People's Republic of China

Email quchanghai@bucm.edu.cn; njtcm@263.net 
and immunity are the three key factors in the occurrence and development of DED. ${ }^{7}$ In 2017, the "TFOS DEWS II Management and Therapy Report" compiled by the Dry Eye Working Group of the International Tear Film and Ocular Surface Association was officially issued, anticorneal inflammation and local anti-immune therapy have been clearly proposed as an effective means to treat severe DED and the application of hypertonic protective agents on the ocular surface has also become the recommended treatment plan for mild DED. ${ }^{8}$ Hypertonicity is the core mechanism in the occurrence and development of DED, and it is one of the main factors that induces corneal inflammation and further damage. ${ }^{7}$ The reverse of the hypertonic state of the ocular surface and the reduction of corneal damage and inflammation under hypertonic stress can effectively block the occurrence and development of DED, thereby reducing the conversion of mild DED to severe DED. Levocarnitine (LC) is a DED hypertonic protection drug recommended in the "Dry Eye Diagnosis and Treatment Guidelines", and its protective effect on corneal and conjunctival epithelial cells under hypertonic conditions has been verified. ${ }^{9,10}$ The researchers successfully prepared the LC eye drops and the protective effect of LC eye drops to ocular surface of mouse dry eye model induced by hyperosmolar saline had been proved. ${ }^{11}$

However, due to the presence of various biological barriers in the eyes, the locally administered drugs can hardly be effectively delivered into the intraocular part. ${ }^{12,13}$ Therefore, how to overcome these ocular obstacles and enhance the bioavailability has become a matter of concern to scientists. Emulsions and ointments were used for increasing the retention and enhance the bioavailability of drugs while they were proved with sides effects such as irritation and blurriness. ${ }^{14}$ Hence, in recent years, the stimuli response of polymer-based drug delivery systems have been explored. These functional biomaterials such as poloxamer possess good mucoadhesive ability and can entrap ophthalmic drugs effectively. ${ }^{15}$ These SPRbased formulations can be divided into different categories, such as thermo-responsive formulations, $\mathrm{pH}-$ responsive formulations and ion-responsive formulations. As one of the new dosage form, the temperature-sensitive in-situ gel is in a solution state at room temperature with good fluidity which is convenient for the administration of eye drops and the spread of the drug on the ocular surface; due to the influence of the temperature of the ocular surface, the drugs immediately undergo phase transition and form a hydrogel on ocular surface which prolong the retention time of the drug on the ocular surface and is conducive to the release and absorption of the drug. ${ }^{16,17}$ It has a hydrophilic three-dimensional network structure and high water content, which is convenient for drug loading and release; the carrier material it used has strong affinity with mucosal tissues and good biocompatibility. ${ }^{18}$ It can achieve different release effects of medicinal active ingredients through regulation. Therefore, the temperaturesensitive in-situ gel is particularly suitable for the treatment of ocular surface diseases such as DED.

This research focuses on the temperature-sensitive insitu gel with LC as the main drug (LCTG) and the in vitro release and eye irritation of the preparation were investigated. The comparison between LC solution and LCTG was made to verify the rationality of the choice of the dosage form. The pharmacodynamics of LCTG was evaluated through the DED animal model.

\section{Materials and Methods}

\section{Materials}

The levocarnitine APIs (purity $>98.8 \%$ ) were supplied by Northeast Pharmaceutical Group (Liaoning, China) and the reference substances of levocarnitine were purchased from Push Bio-technology (Chengdu, China). Poloxamer 407 (P407) and poloxamer 188 (P188) were bought from BASF (Ludwigshafen, Germany). Sodium hyaluronate (HA-Na) and sodium heptanesulfonate (purity: 99\%) were purchased from Sun chemical technology (Shanghai, China) while sodium carboxymethylcellulose (CMC-Na) was acquired from Shenguang Edilble Chemicals (Shanghai, China). Fluorescein sodium (FLS) was supplied by yuanye Bio-Technology (Shanghai, China). Benzalkonium chloride (BAC) was purchased from Sigma (USA). $0.9 \%$ sodium chloride injection was bought from Shijiazhuang No.4 pharmaceutical (Hebei, China). Matrix metalloproteinase (MMPs-3 (1:400), MMPs-9 (1:400)), Periodic Acid-Schiff stain (PAS) kit, FAS eyeball fixative, hematoxylin-Ihong dyeing solution as well as $\mathrm{Cy} 3$ conjugated Goat Anti-rabbit IgG (1:300) and Cy 3 conjugated Goat Anti-mouse $\operatorname{IgG}(1: 300)$ were all supplied by Saville biotechnology (Hubei, China). The phenol red cotton thread was bought from Jingming new technological (Tianjin, China). Ethanol, xylene, hydrochloric, neutral balsam and ammonium hydroxide (analytical grade) were acquired from Sinopharm Chemical Reagent (Shanghai, China). Ethylene diamine tetraacetic 
acid (EDTA) was purchased from ASRESCO Inc. HPLC grade acetonitrile and methanol were obtained from Thermo Fisher Scientific (Massachusetts, USA).

The New Zealand rabbits $(2.3 \sim 2.5 \mathrm{~kg})$ were provided by Beijing jinmuyang; 60 healthy female BALB/c mice, 8 weeks old (SPF grade) were provided by SPF Biotechnology (Beijing, China).

\section{Formulation Preparation}

HA-Na, CMC-Na, P407 and P188 were used as accessories to prepare LCTG. Briefly, $0.02 \%$ amount of HA$\mathrm{Na}$ and $0.1 \%$ amount of CMC-Na were dispersed in distilled water at room temperature until complete swelling. Then, 20.81\% amount of P407 and 3.46\% amount of P188 was added under complete agitation. The mixture was put in a sealed container and stored at $4{ }^{\circ} \mathrm{C}$ until a clear solution was obtained (at least for $24 \mathrm{~h})$. Thereafter, LC (1\%) was added into the solution under continuous stirring until a clear solution was formed. Then the LCTG formulations were hermetically stored at $4^{\circ} \mathrm{C}$ for further use.

\section{In vitro Release Studies}

$5 \mathrm{~g}$ of prepared LCTG was equilibrated at $34 \pm 0.5^{\circ} \mathrm{C}$ in a Water-bathing Constant Temperature Vibrator (Guowang, China) to allow gel formation. Then, $150 \mathrm{~mL}$ of dissolution medium (dissolving $6.78 \mathrm{~g}$ sodium chloride, $0.084 \mathrm{~g}$ Calcium chloride dihydrate and $1.38 \mathrm{~g}$ potassium chloride in water to make $1 \mathrm{~L}$ ) at $34^{\circ} \mathrm{C}$ was added into the vessel and the device side-to-side oscillating at 100 $\mathrm{r} \cdot \mathrm{min}^{-1}$ to investigate the release behavior. Samples were collected at 10, 25, 40, 60,90, 120, 180 and 240min by extracting $2 \mathrm{~mL}$ of dissolution medium and the same volume and temperature of dissolution medium were added immediately. The collected sample was centrifuged at $4950 \mathrm{r} \cdot \mathrm{min}^{-1}$ for 20 minutes. The concentration and cumulative dissolution rate of LC were measured by HPLC system. The chromatographic conditions are as follows:

Agilent Zorbax SB-C ${ }_{18}(250 \mathrm{~mm} \times 4.6 \mathrm{~mm}, 5 \mu \mathrm{m})$ was used as the chromatographic column. The mobile phase was methanol-phosphate buffer $(10 \mathrm{~mL}$ of phosphoric acid was added to $1900 \mathrm{~mL}$ water, about $100 \mathrm{~mL}$ of sodium hydroxide solution was used to adjust the $\mathrm{pH}$ value to 2.4 and $1.1 \mathrm{~g}$ of sodium was added) $(15: 85)$ with a flow rate of $1 \mathrm{~mL} \cdot \mathrm{min}^{-1}$. The column temperature was $25^{\circ} \mathrm{C}$ with a detective wavelength of $225 \mathrm{~nm}$. And the injected quantity was $20 \mu \mathrm{L}$.
Then the in vitro dissolution rate - time curve was plotted, as follow:

$$
F=C_{t} \times V_{0}+V \times \Sigma C_{i} /(W \times m)
$$

Where $C_{t}$ is the drug concentration at $t, V_{0}$ represents the volume of dissolution medium in the vessel, $V$ represents the extracted volume of dissolution medium, $C_{i}$ is the drug concentration before $t, W$ describes the drug content in LCTG, $m$ is the weight of LCTG and $F$ represents the cumulative dissolution rate.

Data obtained from in vitro drug release studies were plotted in various kinetic models: Zero order model: $F=K \mathrm{t}$, First-order model: $\ln (100-F)=-K \mathrm{t}$, Higuchi model: $F=K \mathrm{t}^{1 / 2}$, Ritger-Peppas model: $\ln F=K \ln t+\mathrm{C}$.

\section{The Eye Irritation Studies}

Four rabbits were proved with no eye diseases by a slit lamp microscope (model is YZ3, 66Vision Tech, China). $40 \mu \mathrm{L}$ of LCTG $\left(10 \mathrm{mg} \cdot \mathrm{mL}^{-1}\right)$ was administrated in the conjunctival sac of the left eyes and $40 \mu \mathrm{L}$ of normal saline injection was administrated in the conjunctival sac of the right eyes as control. After administration, the rabbits' eyes were passively closed for ten seconds. The medication method was 4 times a day and $4 \mathrm{~h}$ between medications for 7 days.

\section{Draize Test}

For evaluating the irritation potential of the LCTG in contact with eyes, the Draize test was done. Examination of the eyes was finished before the delivery and 1, 2, 4, 24, 48 and $72 \mathrm{~h}$. The ocular changes were recorded by the standard scoring system designed for this test as Supplement Table 1. The score of cornea, iris and conjunctiva was added as comprehensive grade of each eye stimulation response. Then the eye irritation of LCTG was evaluated according to the evaluation criteria in supple ment Table 2.

\section{Fluorescein Sodium (FLS) Staining Test}

After each examination of the Draize test, the 1\% FLS (w/v) solution was given into the lower eyelid conjunctival sac of the rabbits. Then the cobalt blue light of a slit lamp microscope was used to observe whether the corneal epithelium showed positive staining after $60 \mathrm{~s}$.

\section{Preparation of Paraffin-Embedded Sections of Eyeballs}

The rabbits were put to death after the above experiments and the eyeballs were immediately removed. Then the 
eyeballs were put in the eyeball fixation solution for more than 24 hours in order to preserve the structure of the eyeballs and prevent the rupture of the retina. After that, the eyeballs were dehydrated with graded ethanol $(75 \%, 85 \%$, $90 \%, 95 \%, 100 \%, 100 \%)$. Then, eyeballs were immersed thrice in alcohol benzene, xylene I and xylene II for 5 to 10 min each. Before paraffin embedding, eyeballs were transferred thrice to pure paraffin wax for $1 \mathrm{~h}$ each. For each eyeball, $5 \mu \mathrm{m}$ sections were cut. The slides were collected from the water bath and dried at $60^{\circ} \mathrm{C}$ to promote adhesion. All slides were stored at room temperature.

\section{Hematoxylin-Eosin (HE) Staining}

HE staining was performed on the slides prepared above. The morphology and structure of the cornea were observed with an optical microscope (model is NIKON ECLIPSE CI, Nikon, Japan) and photographs were recorded. Case Viewer software (Danjier Ltd, Jinan, China) was used to measure the thickness of the central corneal epithelial layer, and each slice was measured 3 times at different parts of the central cornea, and the results were averaged.

\section{Evaluation of Retention on the Rabbit's Ocular Surface}

Due to the non-fluorescence property of LC, FLS was chosen to assess the retention time as a common kind of fundus contrast agent. ${ }^{19}$ Preparation method of FLS thermosensitive in situ gel (FLSTG) was the same as the LCTG. Then, $1 \mathrm{~g}$ of FLS was precisely measured and $0.9 \%$ sodium chloride solution was added to make it $100 \mathrm{~mL}$ as a FLS solution. A healthy rabbit was taken and anesthetized by intraperitoneal injection of $10 \%$ chloral hydrate. The left eye was dropped with $20 \mu \mathrm{L}$ of FLSTG, and the right eye was dropped with $20 \mu \mathrm{L}$ of FLS solution as a control. The rabbit eyes were made passive close after administration for $10 \mathrm{~s}$ and started timekeeping. At the predetermined time of 1, 3, 5, 10, 15, 20 and $25 \mathrm{~min}$, the continuous fluorescent layer on the surface of the rabbit cornea was observed by a BQ 900 slit lamp with cobalt blue light (Haag Streit, Switzerland). The disappearance time of the fluorescent layer represented the retention time on the ocular surface. ${ }^{20}$

\section{Pharmacodynamics Evaluation of LCTG Establishment of Mouse Dry Eye Disease (DED) Model $^{21}$}

Sixty healthy female BALB/c mice without eye diseases were numbered in sequence. Fifteen mice were randomly selected as the normal group which did not receive any treatment and were bred normally for 14 days; the other mice were given $0.2 \% \mathrm{BAC}$ solution (w/v) in both eyes, twice a day (at an interval of more than $10 \mathrm{~h}$ each time), $5 \mu \mathrm{L}$ each time, continuous eye drops for 14 days. On the 15th day, the tear secretion and corneal fluorescein sodium staining in both eyes of all mice were detected $\left(n_{\text {normal }}=30\right.$, $n_{\text {model }}=90$ ).

\section{Medication Method}

After modeling, the mice were randomly divided into groups named model group, gel group and solution group with 15 mice in each group, respectively. The normal and the model group were both given physiological saline while the gel group was given LCTG, and the solution group was given LCS $\left(10 \mathrm{mg} \cdot \mathrm{mL}^{-1}\right)$. The administration method was eye drops with 4 times a day, $5 \mu \mathrm{L}$ of each time for 7 consecutive days. In each group, 6 mice were randomly selected after 3 and 7 days of the administration to detect the amount of tear secretion and corneal FLS staining in both eyes $(n=12)$, and 3 mice were randomly selected to extract eye tissue for lacrimal and corneal HE staining and TUNEL staining. Corneal immunofluorescence staining and conjunctival PAS staining were performed on mice removed eye tissues after 7 days of administration.

\section{Tear Secretion Test}

$1 \%$ sodium pentobarbital solution $\left(0.005 \mathrm{~mL} \cdot \mathrm{g}^{-1}\right)$ was injected into the intraperitoneal cavity of the mouse. Then the mouse head was fixed after anesthesia. The phenol red cotton thread was used and the length of the wet part (from yellow to red) was measured by a vernier caliper after $15 \mathrm{~s}$.

\section{Corneal FLS Staining Test}

An appropriate amount of 1\% FLS solution was instilled into the mouse eye surface. After $60 \mathrm{~s}$, the eye surface was washed with normal saline. Slit lamp cobalt blue light was used to observe the staining of the corneal epithelium. The cornea was divided into 4 quadrants, each quadrant was scored separately from 0 to 4 , and then the 4 quadrant scores were added together to obtain the final corneal staining score. The scoring criteria for corneal fluorescein sodium staining were as follows: positive fluorescent plaques, 4 points; very dense punctate fluorescence, 3 points; denser punctate fluorescence, 2 points; weak and sparse punctate fluorescence, 1 point; no fluorescence, 0 points. 


\section{Preparation of Paraffin-Embedded Sections of the Eyeball and Lacrimal Gland}

The normal saline was injected into the subconjunctiva of the lateral canthus of the mouse until the eyeball protruded. The skin was cut along the upper and lower orbital edges with a micro scissor. Then, eye tissues including the eyelid and conjunctiva were removed. The suborbital lacrimal gland was gently grasped with micro tweezers. At last, these tissues were made into paraffin-embedded sections of the eyeballs and lacrimal glands.

\section{HE Staining of Cornea and Lacrimal Gland}

HE staining was performed on paraffin sections of the eyeball and lacrimal gland. The morphology and structure of the cornea and lacrimal gland were observed with an optical microscope, and the results were photographed. Case Viewer software was used to measure the thickness of the central corneal epithelial layer. Each slice was measured 3 times at the central cornea, and the results were averaged.

\section{Corneal Terminal dUTP Nick-End Labeling (TUNEL) Staining}

TUNEL staining was performed on the paraffin sections of the eyeballs using an In Situ Cell Death Detection Kit (Roche, Switzerland) and the apoptosis of corneal epithelial cells was observed with a fluorescence microscope (model is NIKON ECLIPSE CI, Nikon, Japan) which results were photographed. Three different fields of view were selected for each slice to count, and the apoptosis rate of the corneal epithelial cells was calculated. Then the results were averaged.

\section{Corneal Immunofluorescence Staining}

Immunofluorescence staining was performed on the paraffin sections of the eyeballs, and the expression of MMP-3 and MMP-9 in corneal epithelial cells was observed with a fluorescence microscope and photographed and recorded.

\section{Periodic Acid-Schiff (PAS) Staining of Conjunctiva}

PAS staining was performed on the paraffin sections of the eyeballs, and the number of goblet cells in the conjunctiva was observed with an optical microscope and photographed and recorded.

\section{Statistical Method}

The experimental data of the measurement data were expressed by (mean \pm standard deviation), and the experimental data of the grade data are expressed by the mean value (minimum $\sim$ maximum). The results of tear secretion, corneal fluorescein sodium staining score, central corneal epithelial layer thickness, corneal epithelial cell apoptosis rate and other results were statistically analyzed using GraphPad Prism software. Measurement data were compared between the two groups by $t$ test. And the comparison between multiple groups was by variance Analysis and Tukey's multiple comparisons; non-parametric test was used for comparison of grade data between two groups, the non-parametric test and Dunn's multiple comparison were used for comparisons between groups, and $\mathrm{P}<0.05$ was considered statistically significant.

\section{Results}

\section{The in vitro Release Studies}

The photo before and after gelation of LCTG is shown in Figure 1. The cumulative release-time curve of LCTG in vitro is shown in Figure 2. The result showed that the release of LCTG was basically complete in $3 \mathrm{~h}$. Data obtained from in vitro drug release studies were plotted in various kinetic models and the fitting results are shown in Table 1.

\section{The Eye Irritation Studies Draize Test}

There was no congestion or edema in the conjunctiva, normal iris, clear and transparent cornea, no edema, and occasionally a small amount of secretion was observed in the corner of the eye in both gel group and control group. The comprehensive scoring results of eye irritation response are shown in Table 2 and the

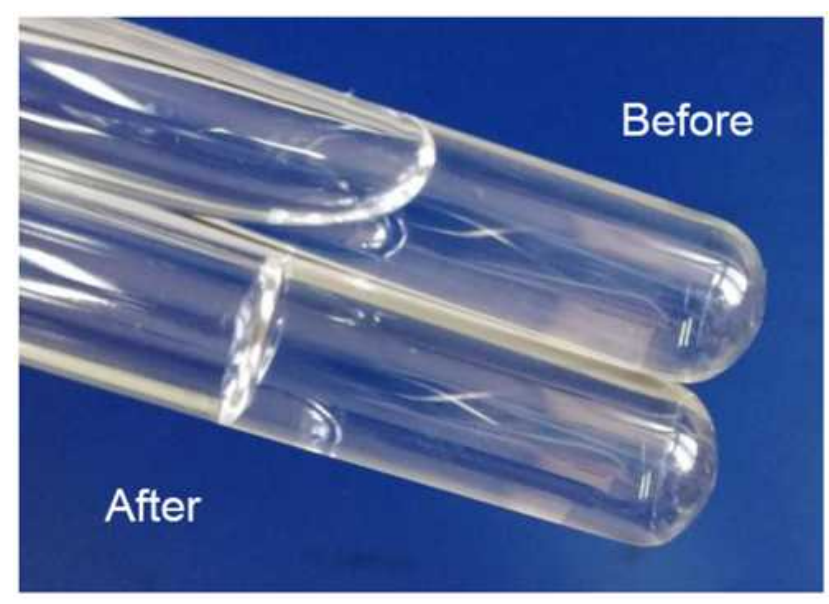

Figure I The photo of LCTG before and after gelation. 


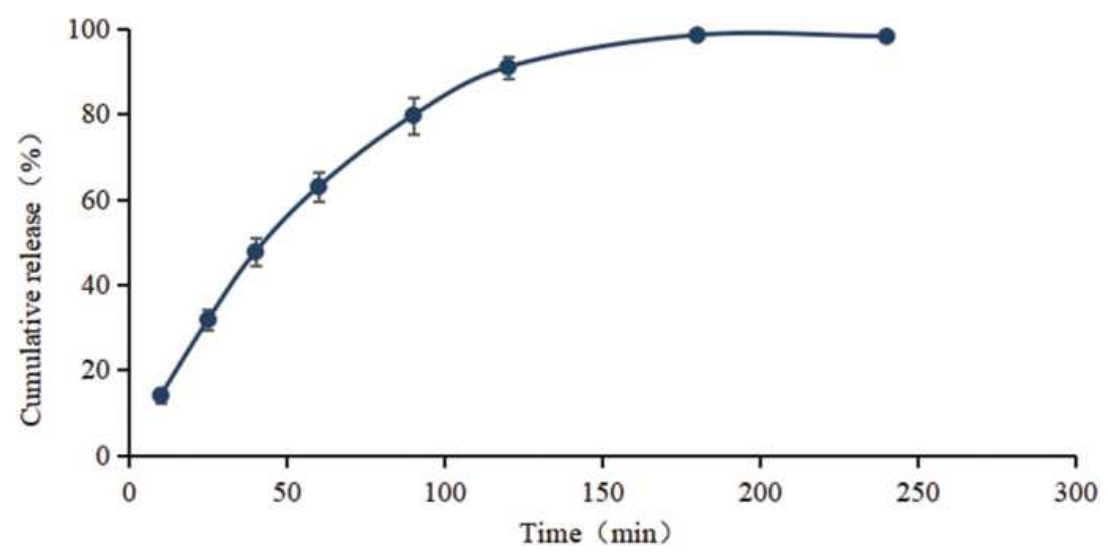

Figure 2 Cumulative release-time curve of LCTG ( $n=5, \bar{X} \pm s$ ).

results of eye irritation response examination of rabbits on the 7th day of administration are shown in Figure 3.

The comprehensive score of eye irritation response of any rabbit in the gel group at each observation time was $\leq 1$ point. According to the eye irritation evaluation standard in supplement Table 2, it indicated nonirritation of preparations when the comprehensive score of eye irritation response was 0 to 3 points. Hence, the results show that prepared ophthalmic LCTG preparation had no irritation to rabbit eyes after multiple administrations.

Table I Mathematical Model Fitting Results of LCTG

\begin{tabular}{|l|c|}
\hline Model Equations & LCTG \\
\hline Zero order & $F=0.4905 t+23.998(r=0.9353)$ \\
First order & $\ln (100-F)=-0.0236 t+4.8935(r=0.9918)$ \\
Higuchi & $F=8.6887 \mathrm{t}^{1 / 2}-8.8348(r=0.9833)$ \\
Ritger-Peppas & $\ln F=0.6919 \ln \mathrm{t}+1.1938(r=0.9837)$ \\
\hline
\end{tabular}

Fluorescein Sodium Staining (FLS) Test

FLS solution was put into the rabbit conjunctival sac after each time of Draize eye irritation test. There were less than 5 punctate stains that can be observed in the corneal area, occasionally, in both gel group and control group, which represented negative results. In consequence, these results indicated that LCTG has no damage to the cornea after multiple administrations. The results of corneal FLS staining inspection on the 7 th day of administration of rabbits are shown in Figure 4.

\section{The Results of Corneal Histopathological Examination and Central Corneal Epithelial Thickness Measurement}

The results of HE staining of the gel group and control group are shown in Figure 5. The following illustrations showed that the structure of each layer of the rabbit's cornea in the gel group and control group was integrated and the boundaries between the layers were obvious. No necrosis or shedding can be observed on the corneal epithelial cell layer, and the stroma has no obvious

Table 2 The Comprehensive Scoring Results of Eye Irritation Response

\begin{tabular}{|c|c|c|c|c|c|c|c|c|c|c|c|c|c|c|c|}
\hline \multirow[t]{2}{*}{ The group } & \multirow[t]{2}{*}{ Number } & \multicolumn{14}{|c|}{ Observation Time } \\
\hline & & $\mathbf{O d}$ & I d & $2 d$ & $3 d$ & $4 d$ & $5 \mathrm{~d}$ & $6 \mathrm{~d}$ & $7 \mathrm{~d}$ & I h & $2 \mathrm{~h}$ & $4 \mathrm{~h}$ & $24 \mathrm{~h}$ & $48 h$ & $72 \mathrm{~h}$ \\
\hline \multirow[t]{4}{*}{ Gel group } & I & 0 & 0 & 0 & 0 & I & I & 1 & 0 & 0 & 0 & 0 & 0 & I & I \\
\hline & 2 & 0 & 0 & 0 & 0 & 0 & 0 & I & I & 0 & 0 & I & 0 & 0 & 0 \\
\hline & 3 & 0 & 0 & I & 0 & I & 0 & 0 & 0 & 0 & 0 & 0 & 0 & 0 & 1 \\
\hline & 4 & 0 & 0 & 0 & 0 & 0 & 0 & 0 & 0 & 0 & 0 & 0 & 0 & 0 & 0 \\
\hline \multirow[t]{4}{*}{ Control group } & I & 0 & 0 & 0 & 0 & 0 & 0 & 1 & 0 & 0 & 0 & 0 & 0 & 0 & 0 \\
\hline & 2 & 0 & 0 & 0 & 0 & 0 & 0 & 0 & 0 & 0 & I & 0 & 0 & 0 & 0 \\
\hline & 3 & 0 & 0 & 0 & 0 & I & I & 0 & 0 & 0 & I & 0 & 0 & 1 & 1 \\
\hline & 4 & 0 & I & 0 & 0 & I & 0 & I & 0 & 0 & 0 & 0 & 0 & 0 & 0 \\
\hline
\end{tabular}




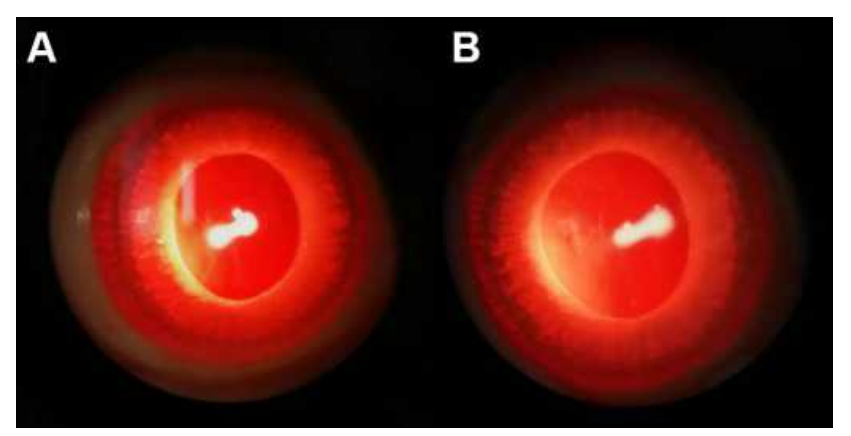

Figure 3 The representative result of Draize test on 7th day (A:the gel group, $\mathbf{B}$ : the control group).

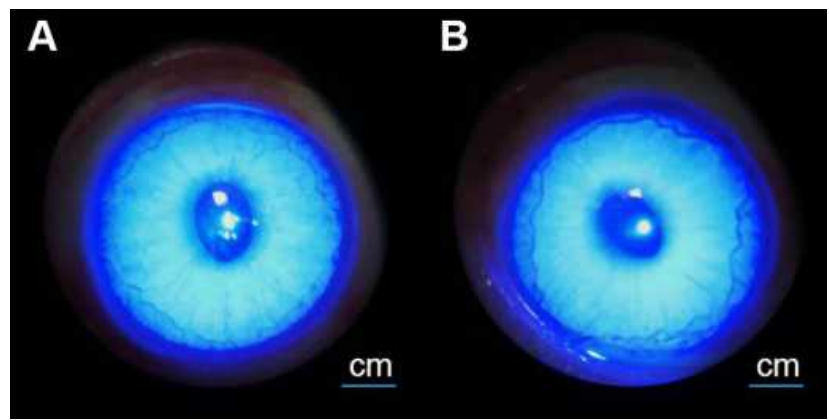

Figure 4 The representative result of FLS test on 7th day (A:the gel group, B:the control group).

inflammatory cell infiltration and proliferation. What is more, there were no histopathological changes caused. Case Viewer software was used to measure the thickness of the central corneal epithelial layer of rabbits. The thickness of the central corneal epithelial layer of rabbits in the gel group and control group were $20.65 \pm 0.89 \mu \mathrm{m}$ and $20.03 \pm 0.89 \mu \mathrm{m}(\mathrm{n}=4, \pm s)$, respectively, and showed no significant statistical difference $(\mathrm{P}>0.05)$. These results all indicated that the LCTG preparation had no irritation to rabbit eyes.

\section{The Pharmacodynamics Evaluation of LCTG}

\section{The Establishment of Mouse Dry Eye Model}

The ocular surface of mice had been tarnished after 2 weeks of treatment of $0.2 \%$ BAC solution. The tear secretion of the normal group and the model groups were $7.02 \pm$ $1.15 \mathrm{~mm}(\mathrm{n}=30, \pm s)$ and $5.14 \pm 1.15 \mathrm{~mm}(\mathrm{n}=90, \pm s)$, respectively. The tear secretion of the model mice was significantly lower than the normal group $(\mathrm{P}<0.001)$. It can be found that the corneal area of the model mice was stained with plaque-like fluorescence after staining the ocular surface of the mice with a $1 \%$ FLS solution and the results are shown in Figure 6. The comprehensive score of ocular surface staining of the mice was recorded as $0.63(0 \sim 5)$ of the normal group and $5.31(0 \sim 13)$ of the model group. Compared with normal mice, the corneal FLS staining score of the model group was significantly higher $(\mathrm{P}<0.001)$. The above results showed that the $0.2 \%$ BAC solution can inhibit the secretion of mouse tears and destroy the integrity of the mouse cornea. And this DED animal model can be used for the pharmacodynamic evaluation study of LCTG.

\section{The Tear Secretion}

The results of tear secretion are shown in Table 3 and Figure 7. After 3 days of the administration, the amount of tear secretion in the gel group was significantly higher than that of the model group and the solution group $(\mathrm{P}<0.001)$. Compared with the normal group, the difference was not statistically significant $(\mathrm{P}>0.05)$. The amount of tear secretion of the solution group increased more slightly compared to the model group, but the difference was not statistically significant $(\mathrm{P}>0.05)$. After 7 days of the administration, the tear secretion of mice in the gel group and solution group was significantly higher than that of the model group $(\mathrm{P}<0.001)$. And the tear secretion of mice in the gel group was higher than that of the normal group $(\mathrm{P}<0.01)$. Compared to 4 days ago, the amount of tear secretion of the model group increased while it was still lower than the normal group $(\mathrm{P}<0.01)$.

The above results indicated that LCTG and LCS can increase the amount of tear secretion of DED model mice, and the LCTG took action faster than LCS.

\section{The FLS Staining of the Corneal}

The staining condition for 7 days of the administration of DED model mice is shown in Figure 8, and the results of the staining score are shown in Table 4 and Figure 9. After 3 days of the administration, the FLS staining score of the gel group was lower than that of the model group $(\mathrm{P}<0.05)$ and there was no significant difference compared with the normal group $(\mathrm{P}>0.05)$. The score value of the solution group was slightly lower than that of the model group with no statistically significant difference $(\mathrm{P}>0.05)$. After 7 days of the administration, there was no statistically significant difference in corneal FLS staining scores among the normal group, model group, solution group and gel group $(\mathrm{P}>0.05)$. 

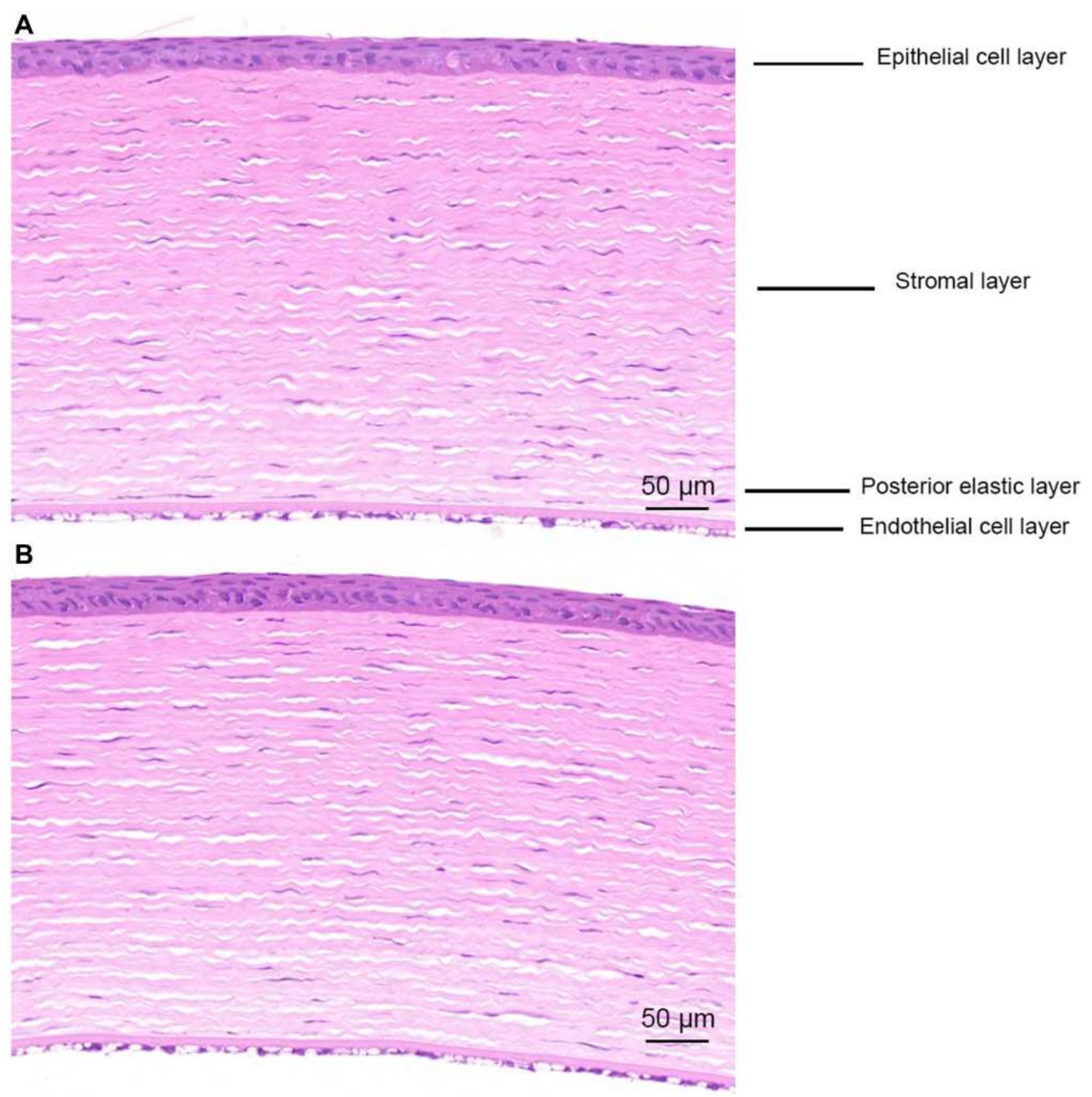

Figure 5 The corneal topographic changes (A:The gel group, B:the control group).

These results indicated that LCTG can effectively improve the impairment of the corneal epithelium of DED model mice and improve the integrity of the corneal epithelium which showed better efficacy than LCS.

\section{The HE Staining}

The results of HE staining of the lacrimal gland are shown in Figure 10. After 3 days of the administration, the cells of the lacrimal gland of the normal group were tightly arranged and the acinar was normal. The cell

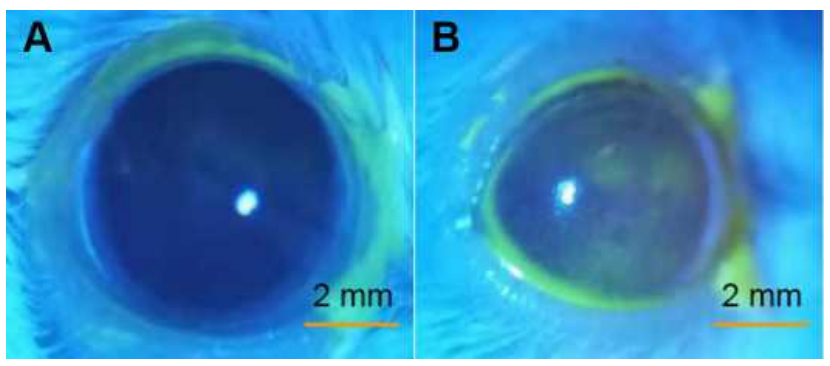

Figure 6 The FLS staining results of groups (A:the normal group, B:the model group). 
Table 3 The Quantity of Tear Fluid of Groups (Mm, $\mathrm{n}=12, \bar{X} \pm s$ )

\begin{tabular}{|l|c|c|c|c|}
\hline Time & $\begin{array}{c}\text { Normal } \\
\text { Group }\end{array}$ & $\begin{array}{c}\text { Model } \\
\text { Group }\end{array}$ & $\begin{array}{c}\text { Solution } \\
\text { Group }\end{array}$ & $\begin{array}{c}\text { Gel } \\
\text { Group }\end{array}$ \\
\hline 3d & $6.73 \pm 0.83$ & $4.84 \pm 0.73$ & $5.10 \pm 0.52$ & $6.43 \pm 0.63$ \\
$7 \mathrm{~d}$ & $6.90 \pm 0.56$ & $6.03 \pm 0.90$ & $7.35 \pm 0.50$ & $7.79 \pm 0.49$ \\
\hline
\end{tabular}

gland cavity of the model and solution group was enlarged and the intercellular space was enlarged while the lacrimal cells of the gel group were tightly arranged and the glandular cavity was only occasionally enlarged. After 7 days of the administration, the lacrimal gland cells of the normal group, the solution group and the gel group were tightly arranged and the acinar cells were normal. The model group showed significant improvement compared with 4 days ago but still did not transform into its normal form.

The results indicated that LCTG and LCS can effectively improve the lacrimal gland morphology of DED model mice. And at the same time, LCTG can promote the faster recovery of injured cells to normal.

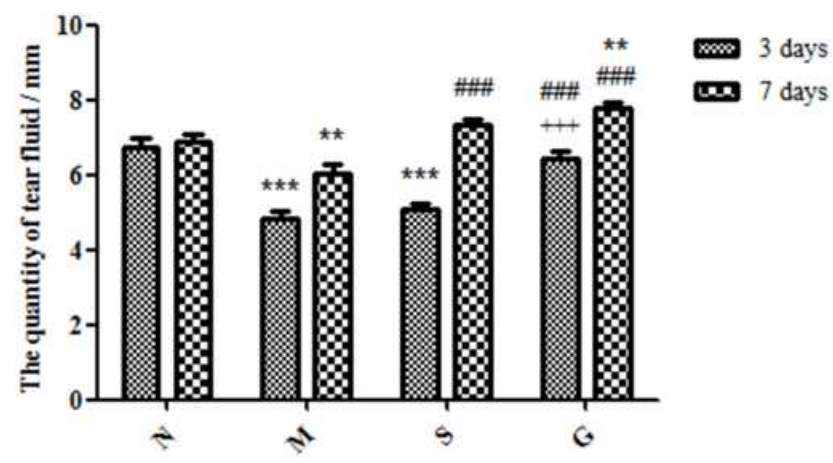

Figure 7 The quantity of tear fluid of groups $(\mathrm{n}=12, \bar{X} \pm s)$. (N: the normal group; (M) the model group; (S) the solution group; (G) the gel group. Compare with $(\mathbf{N})$ $* * * P<0.001$, $* * P<0.01$; Compare with $(\mathbf{M})^{\# \#} p<0.001$; Compare with $(\mathbf{S})^{+++} p<$ 0.001 .).
Table 4 The Consequence Score of Corneal FLS Staining $(\mathrm{n}=$ 12, $\bar{X} \pm s)$

\begin{tabular}{|l|c|c|c|c|}
\hline Time & $\begin{array}{c}\text { Normal } \\
\text { Group }\end{array}$ & $\begin{array}{c}\text { Model } \\
\text { Group }\end{array}$ & $\begin{array}{c}\text { Solution } \\
\text { Group }\end{array}$ & $\begin{array}{c}\text { Gel } \\
\text { Group }\end{array}$ \\
\hline $3 \mathrm{~d}$ & $0.42(0 \sim 1)$ & $3.75(\mathrm{I} \sim 6)$ & $2.58(0 \sim 5)$ & $\mathrm{I} .67(0 \sim 4)$ \\
$7 \mathrm{~d}$ & $\mathrm{I} .17(0 \sim 2)$ & $2.33(\mathrm{I} \sim 5)$ & $1.92(\mathrm{I} \sim 3)$ & $\mathrm{I} .42(0 \sim 2)$ \\
\hline
\end{tabular}

\section{Corneal HE Staining and Central Corneal Epithelial Thickness}

The results of HE staining of the cornea are shown in Figure 11. The measurement results of the thickness of the central corneal epithelial layer are shown in Table 5 and Figure 12. After 3 days of the administration, the corneal stratification of mice in the model group was not clear. However, the flat cells, wing cells and basal cells of the corneal epithelial layer arranged disorderly and the number of cells was relatively few. Besides, the thickness

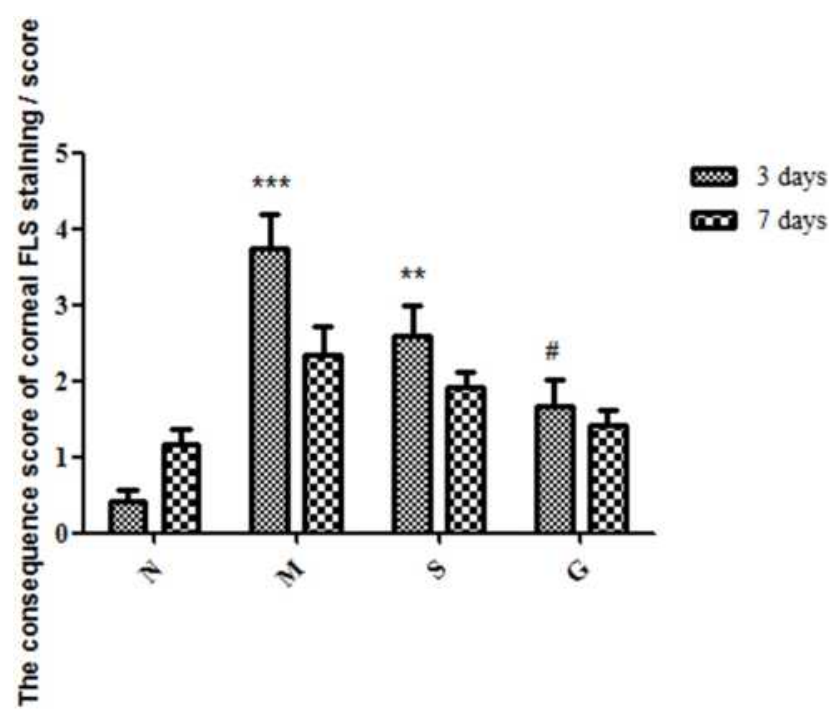

Figure 9 The consequence score of corneal FLS staining $(n=12, x \pm s)$. (N:the normal group; (M) the model group; (S) the solution group; (G) the gel group. Compare with $(\mathbf{N}) * * * P<0.001$, $* * P<0.01$; Compare with $\left.(\mathbf{M})^{\#} P<0.05\right)$.

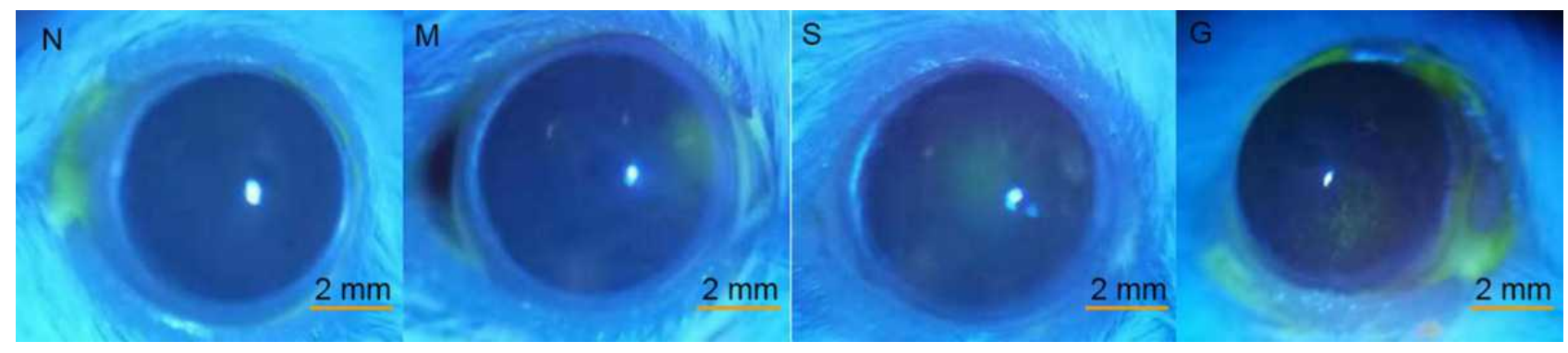

Figure 8 The FLS staining condition of groups (N: the normal group; (M) the model group; (S) the solution group; G: the gel group.). 
$3 d$
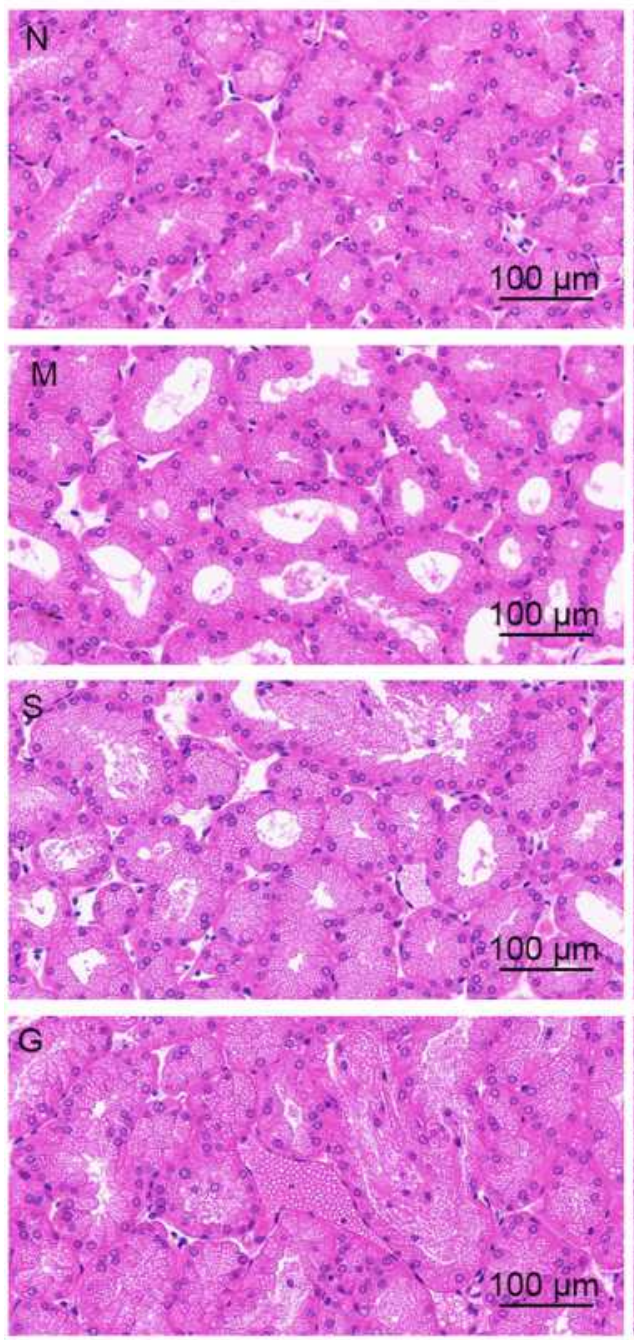

$7 d$
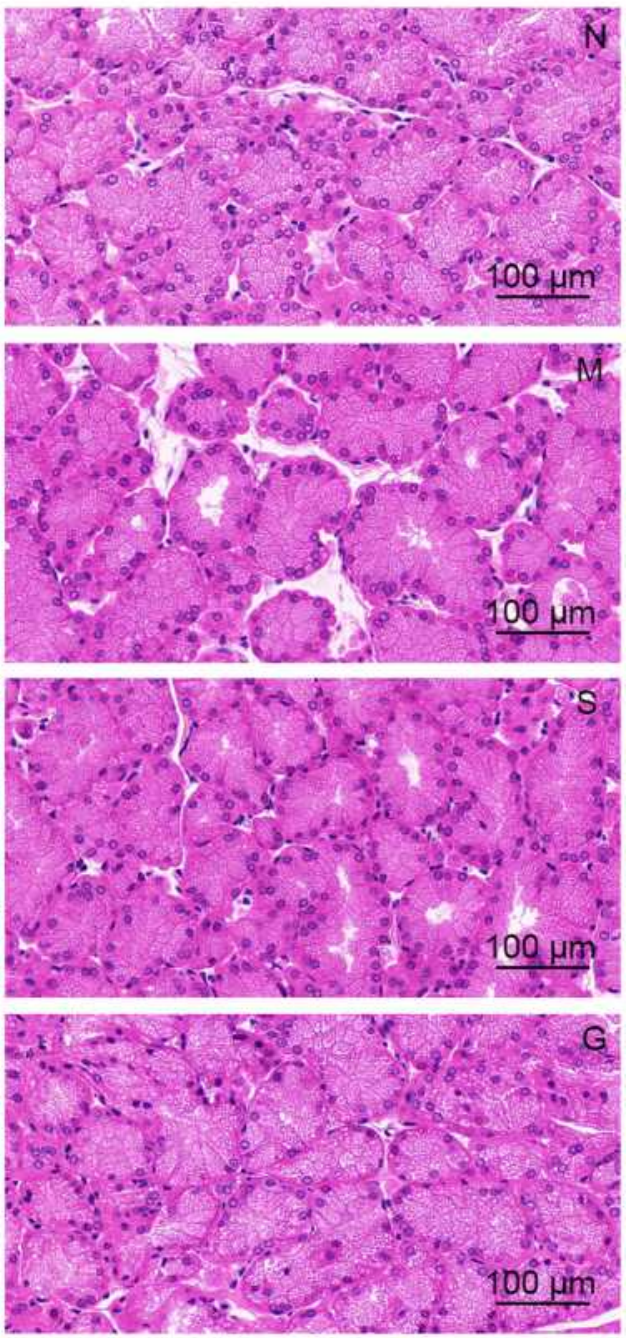

Figure 10 The form of lacrimal gland (N:the normal group; (M) the model group; (S) the solution group; (G) the gel group.).

of the central corneal epithelial layer was lower than that of the normal group $(\mathrm{P}<0.05)$. The corneal epithelial cells of mice in the solution group arranged more regularly. Compared with the model group, the thickness of the central corneal epithelial layer increased slightly but the difference was not statistically conspicuous $(\mathrm{P}>0.05)$. The corneal epithelial cells of the mice in the gel group arranged neatly and morphologically completed. Compared with the model group, the thickness of the central corneal epithelial layer increased $(\mathrm{P}<0.05)$. Compared with the normal group, the thickness of the central corneal epithelial layer was not statistically different $(\mathrm{P}>0.05)$. After 7 days of the administration, the number of corneal epithelial cell layers (4 to 5 layers) of the model group did not return to the normal level (6 to 7 layers). The average thickness of the central corneal epithelial layer of the solution group was greater than $38 \mu \mathrm{m}$. Compared with mice in the normal group, the results were not statistically different $(\mathrm{P}>0.05)$.

The above results show that LCTG and LCS can promote corneal repair in DED model mice, and the efficacy of LCTG is better than LCS.

\section{Corneal TUNEL Staining}

The apoptosis of corneal epithelial cells was shown in Figures 13 and 14 and the results of the apoptosis rate of corneal epithelial cells are shown in Table 6 and Figure 15. After 3 days of the administration, the corneal epithelial cells of the normal group were arranged neatly and apoptotic cells were occasionally seen while more apoptotic 
$3 d$

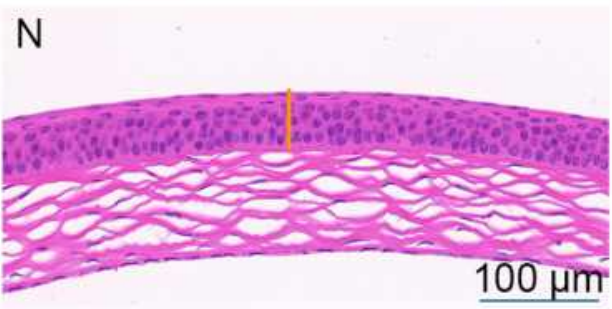

M

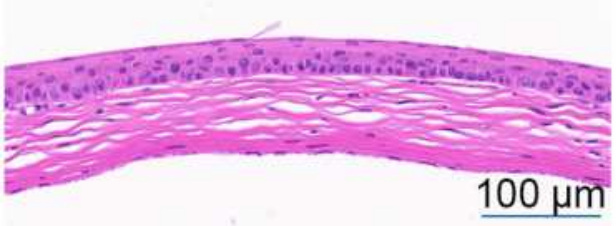

S

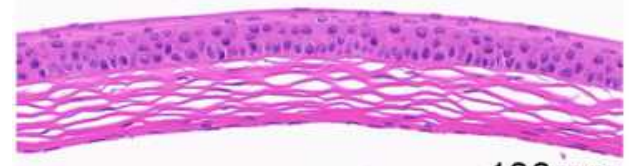

$\underline{100 \mu \mathrm{m}}$

G

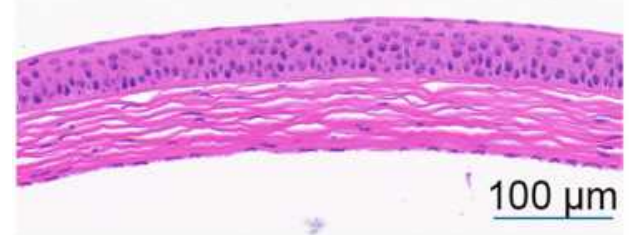

$7 d$

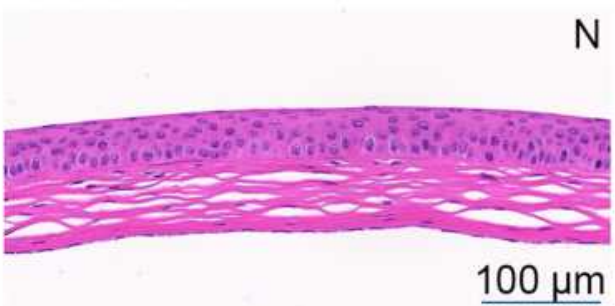

M

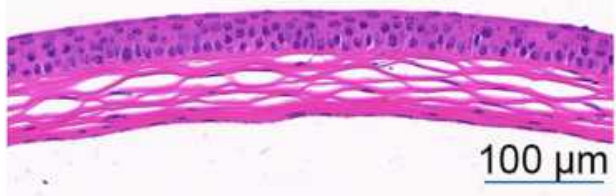

$S$

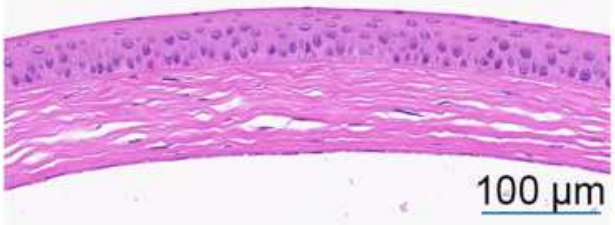

G

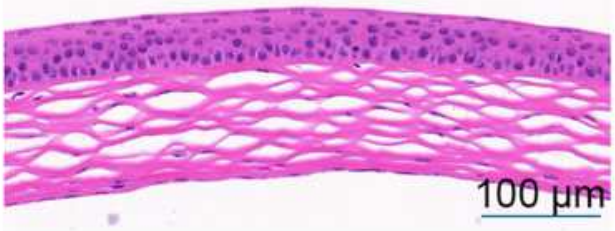

Figure I I The form of cornea (N:the normal group; (M) the model group; (S) the solution group; (G) the gel group. The area marked by yellow line segment represented corneal epithelium layer.

cells can be seen in the model group. Compared with the model group, the apoptosis rate of corneal epithelial cells in the gel group was significantly reduced $(\mathrm{P}<0.05)$. And the apoptosis rate in the solution group was slightly reduced compared with the model group with no statistically significant $(\mathrm{P}>0.05)$. After 7 days of the

Table 5 Measurement Results of Central Corneal Epithelial Layer Thickness $(\mu \mathrm{m}, \mathrm{n}=5, \bar{X} \pm s)$

\begin{tabular}{|c|c|c|c|c|}
\hline Time & Normal & Model & Solution & Gel \\
\hline 3 d & $38.66 \pm 3.07$ & $32.17 \pm 2.67$ & $34.95 \pm 3.72$ & $38.59 \pm 3.44$ \\
$7 \mathrm{~d}$ & $38.90 \pm 2.67$ & $32.91 \pm 3.00$ & $38.02 \pm 4.23$ & $39.25 \pm 2.65$ \\
\hline
\end{tabular}

administration, there was no significant difference in corneal epithelial cell apoptosis in each group ( $\mathrm{P}>0.05)$.

The above results indicated that LCTG can downregulate the apoptosis rate of corneal epithelial cells of DED model mice with better efficacy than LCS.

\section{Corneal Immunofluorescence Staining}

The expression of MMP-3 and MMP-9 in corneal epithelial cells is shown in Figure 16. After 7 days of the administration, there was a trace of MMP-3 expression in the normal group but no MMP-9 expression, while MMP9 of the model group expressed heavily. It was speculated that this phenomenon may be related to the inability of normal cells to produce ProMMP-9. Compared with the 


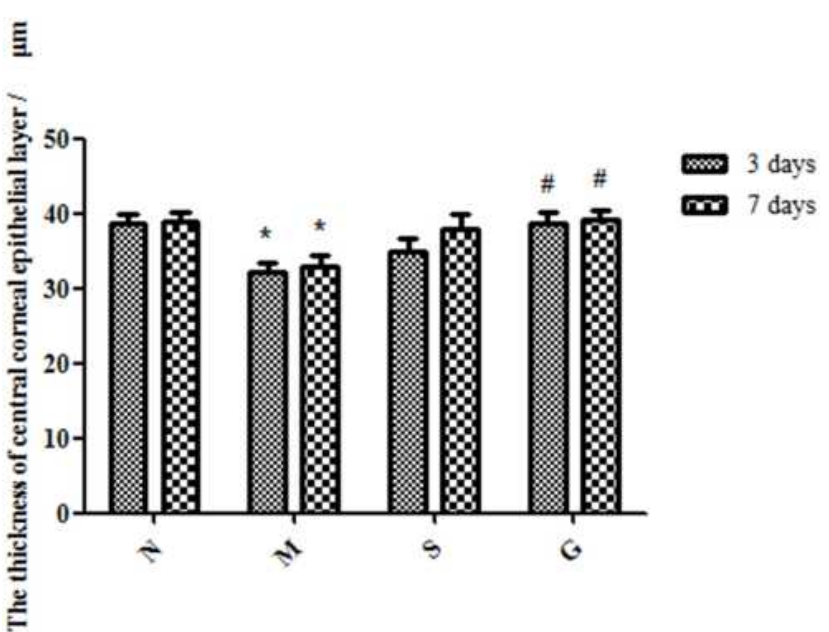

Figure 12 Measurement results of central corneal epithelial layer thickness ( $\mu \mathrm{m}$, $\mathrm{n}=5, \mathrm{x} \pm \mathrm{s}$. (N) the normal group; (M) the model group; (S) the solution group; (G) the gel group. Compared with $(\mathbf{N}) * P<0.05$; Compared with $\left.(\mathbf{M}){ }^{\#} P<0.05\right)$.

TUNEL
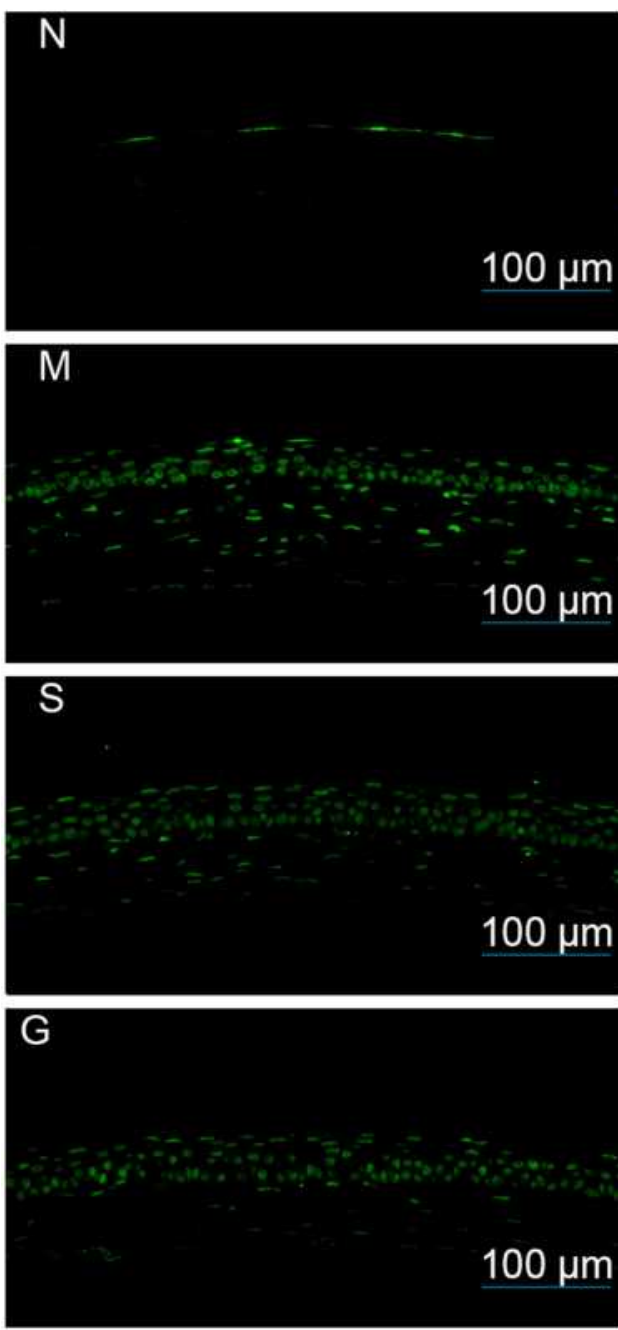

model group, the expression level of MMP-3 in corneal epithelial cells of the gel group and the solution group decreased, of which the level of the gel group was close to the normal group. Besides, there was no expression of MMP-9 in corneal epithelial cells of mice both in the solution group and gel group.

The above results suggested that LCS and LCTG can down-regulate the expression levels of MMP-3 and MMP9 in corneal epithelial cells of DED model mice. And LCTG worked better than LCS.

\section{The Conjunctiva PAS Staining}

The results of PAS staining are shown in Figure 17. After 7 days of the administration, the number of conjunctival goblet cells in the gel group was significantly higher than that in the model group, while the number

\section{Merged with DAPI}
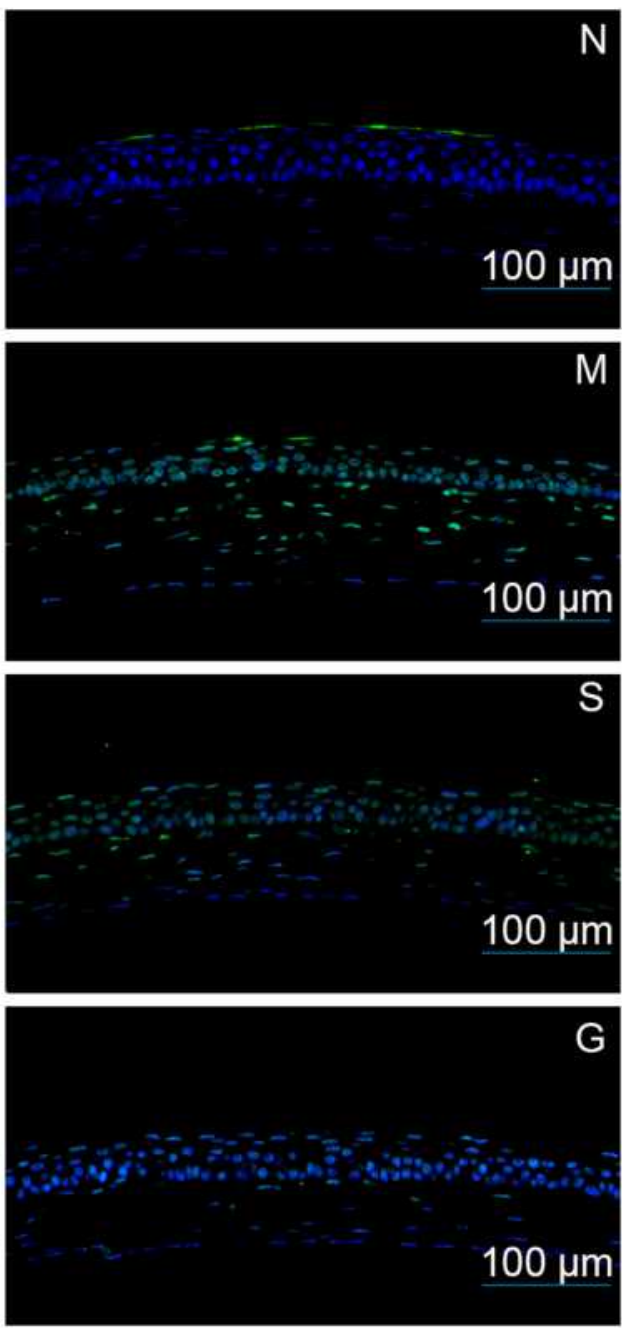

Figure 13 The apoptosis rate of corneal epithelial cells after 3 days of the administrations (N: the normal group; (M) the model group; (S) the solution group; (G) the gel group. The green fluorescence indicated the nucleus of positive apoptotic cells while blue fluorescence represented the nucleus of other cells.) 

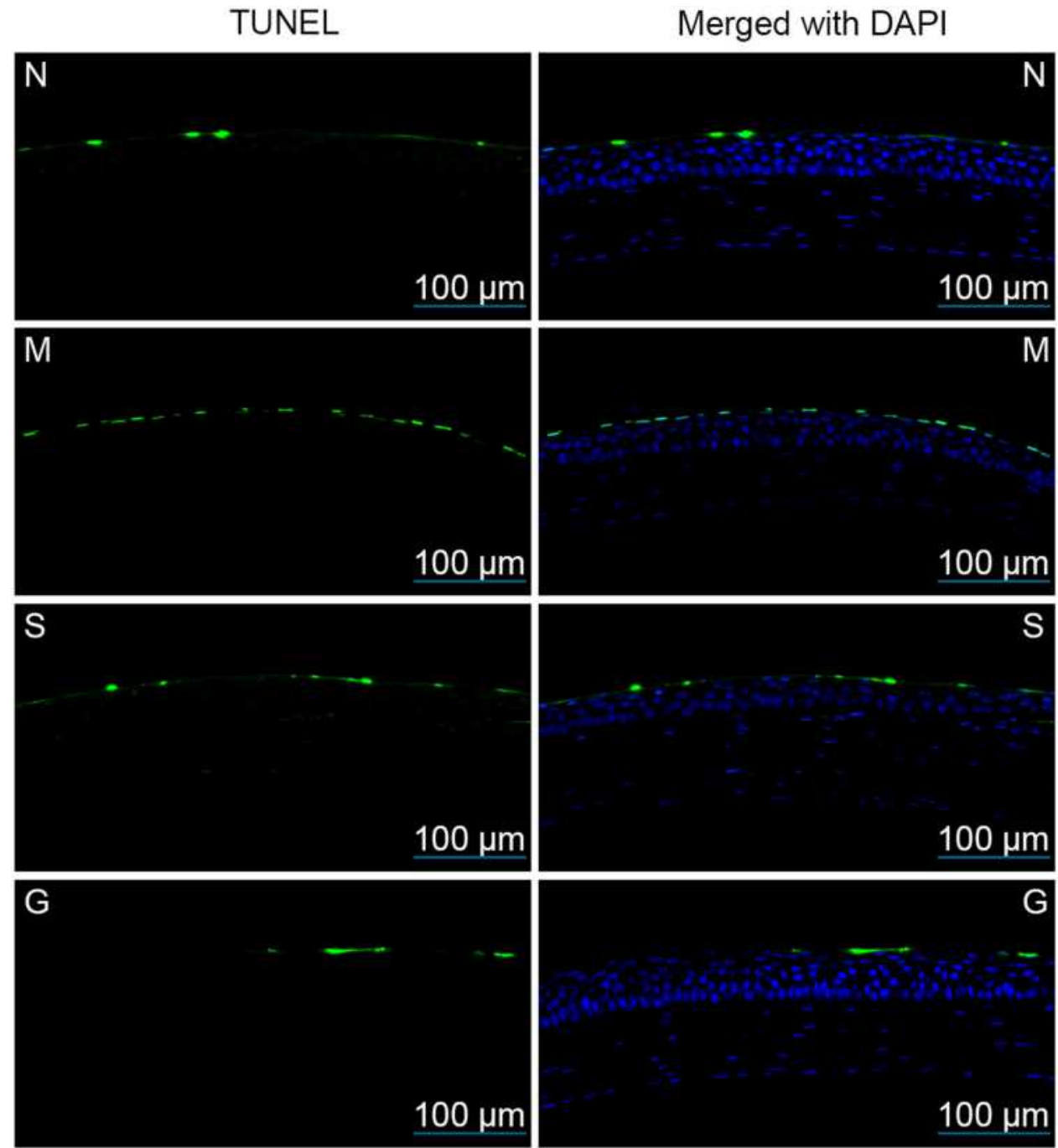

Figure 14 The apoptosis rate of corneal epithelial cells after 7 days of the administrations (N: the normal group; (M) the model group; (S) the solution group; (G) the gel group. The green fluorescence indicated the nucleus of positive apoptotic cells while blue fluorescence represented the nucleus of other cells.).

of conjunctival goblet cells in the solution group did not increase significantly compared with the model group. These results indicated that LCTG can promote the proliferation of conjunctival goblet cells in DED model mice.

Table 6 The Apoptosis Rate of Corneal Epithelial Cells (\%, $\mathrm{n}=$ $3, \bar{X} \pm s)$

\begin{tabular}{|l|c|c|c|c|}
\hline Time & Normal & Model & Solution & Gel \\
\hline $3 \mathrm{~d}$ & $1.98 \pm 1.05$ & $70.93 \pm 7.20$ & $57.12 \pm 14.5 \mathrm{I}$ & $44.18 \pm 5.7 \mathrm{I}$ \\
$7 \mathrm{~d}$ & $\mathrm{I} .60 \pm 1.47$ & $2.75 \pm 1.66$ & $2.48 \pm 2.67$ & $1.80 \pm 1.56$ \\
\hline
\end{tabular}

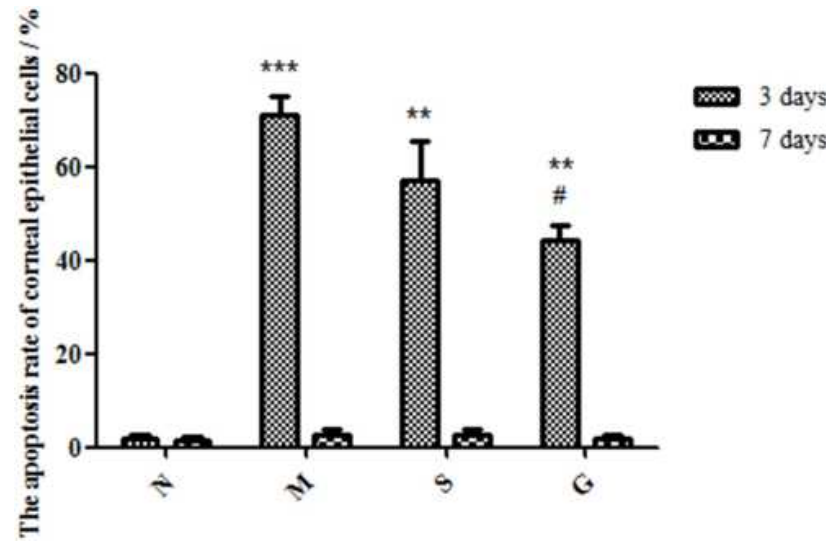

Figure 15 The apoptosis rate of corneal epithelial cells $(n=3, \bar{X} \pm s$. (N) the normal group; (M) the model group; (S) the solution group; (G) the gel group. Compared with $(\mathbf{N}) * * * \mathrm{P}<0.001$, **P $<0.01$; Compared with $(\mathbf{M})^{\#} \mathrm{P}<0.05$.). 

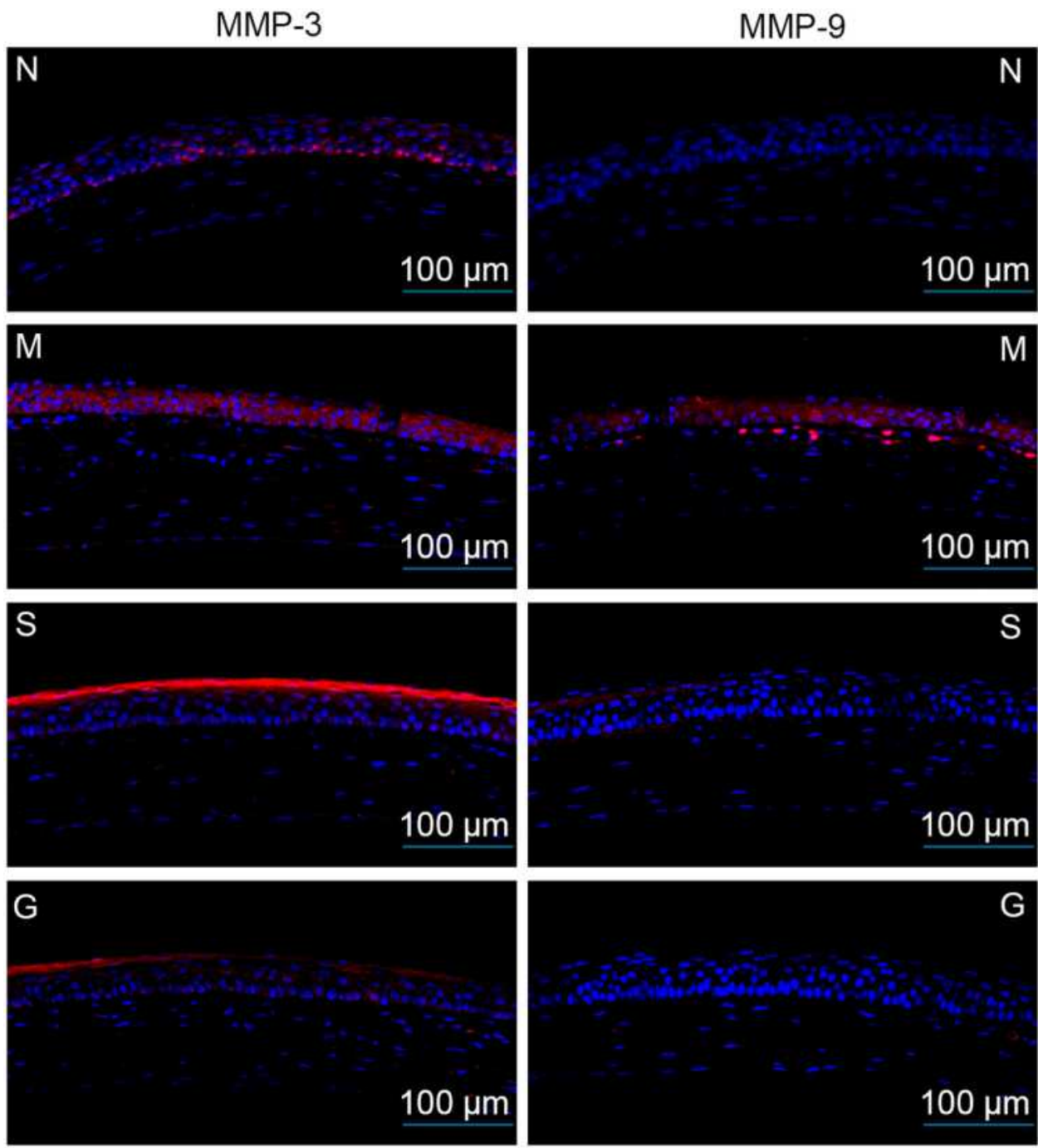

Figure 16 The expression of MMP-3 and MMP-9 in corneal epithelial cells (N: the normal group; (M) the model group; (S) the solution group; (G) the gel group. The blue fluorescence represented the nucleus.).

\section{Discussion}

New technologies have been explored in many researches such as a kind of long-acting mucoadhesive thermogels and gallate-loaded gelatin-g-poly (N-Isopropylacrylamide) for the treatment of DED. As the first recommended drug in "Dry Eye Diagnosis and Treatment Guidelines", the protective effect of LC on corneal epithelial cells under hypertonic state has been verified. ${ }^{22-24}$ Another research group prepared an artificial formulation which also used LC as a part of formulation to help replenish the tear film. ${ }^{25}$ In this study, a kind of thermosensitive in situ gel of LC was prepared which is in a floating condition at room temperature while can form a gel rapidly as soon as dropped in the ocular surface of rabbits. The mechanism of the gelatinization under specific temperature of LCTG was relevant with hydrophobic effect of groups, hydrogen-bond interaction among polymer chains and hydrogen-bond interaction among hydrophilic group. On the one hand, LCTG can give full play to the advantages of direct contact with the ocular surface. On the other hand, it can overcome the disadvantage of frequent administration of other eye drops, help improve the bioavailability and extend the retention time of the drug on the ocular surface. ${ }^{26,27}$ Moreover, the usage of HA-Na in the formulation shows its strong hydrophilic property so that most of tear secretion of rabbits can be absorbed and maintained on the ocular surface for a relatively long period of time. ${ }^{28-30}$

The drug irritation plays an important role in the evaluation of ophthalmic preparations. Because of the high sensitivity of rabbit eyes to drug irritation, they are particularly 

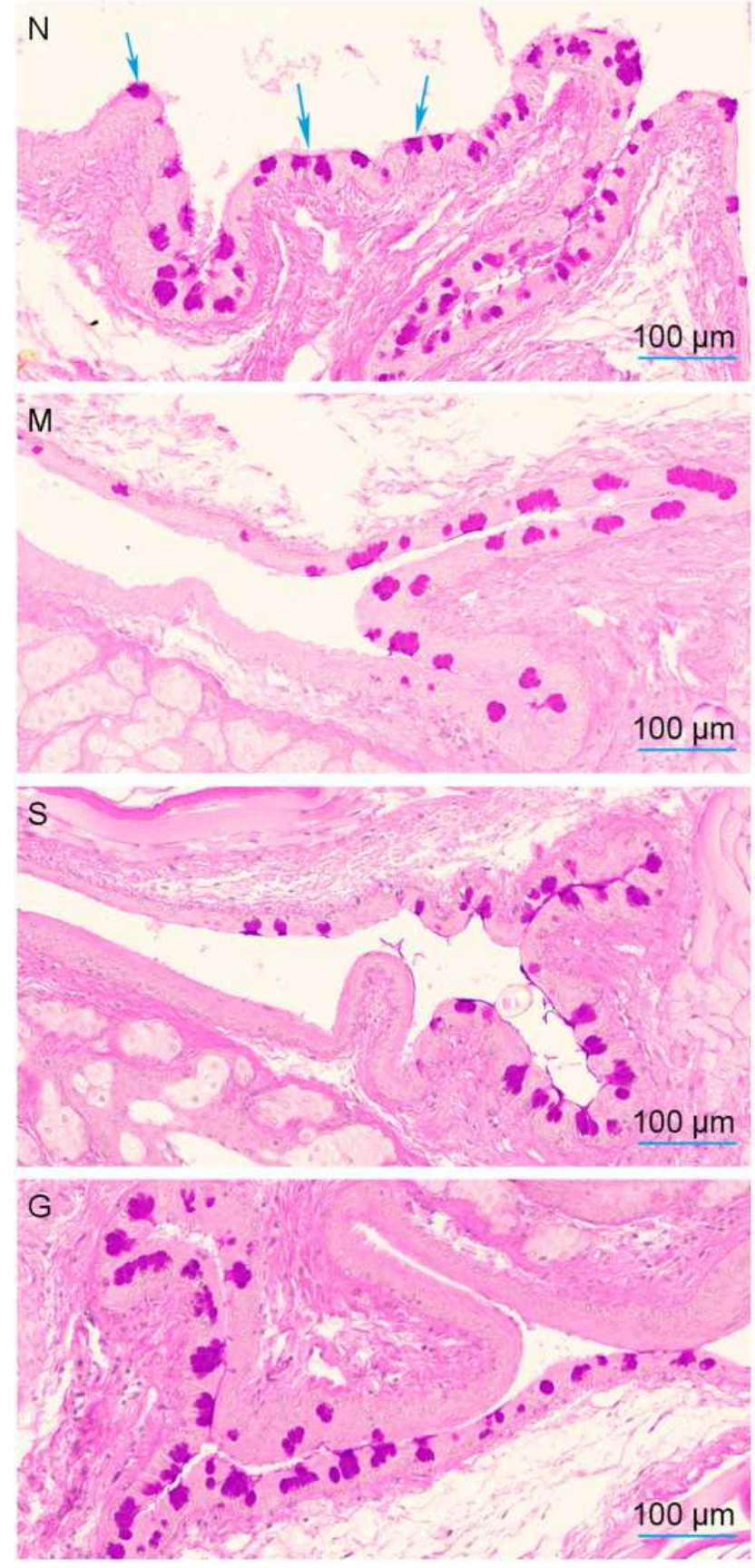

Figure 17 The conjunctival goblet cells after 7 days of the administrations ( $\mathbf{N}$ : the normal group; (M) the model group; (S) the solution group; (G) the gel group. The blue arrows pointed to the conjunctival goblet cells.

suitable for the eye irritation test. The Draize test can provide a comprehensive and systematic evaluation of the inflammatory changes of the iris, conjunctiva and surrounding tissues as well as corneal abrasion. ${ }^{31}$ And LCTG showed no irritation to rabbit eyes compared with saline.

In a previous study, a novel kind of intelligently controlled environmental system was used to induce the DED model. $^{32}$ They found that central corneal epithelial thickness of the DED model mice was reduced and the epithelial cells were of different sizes with poor stratification. Also, the central corneal epithelial thickness of DED model mice in our study was reduced and the stratification of the cornea was not clear. LCS and LCTG can both help promote the recovery of the central corneal epithelial thickness and LCTG showed a better curative effect than LC.

MMP-3 is an important member of the MMPs family. It can degrade a variety of extracellular matrix components and participate in a series of physiological and pathological processes such as tissue morphogenesis, damage repair, and inflammation. MMP-9 gene expression products are mainly produced by macrophages, neutrophils and monocytes. Stimuli such as inflammatory mediators can increase the expression level of mRNA encoded by MMP-9 gene. The possible effect of osmotic protection of LC for treating DED was as follows. First of all, the interaction of LC and pathways of TRPV1 can inhibit inflammatory response to protect the cornea epithelial cells. Secondly, it can inhibit the gene expression, protein synthesis and enzyme activity of MMPs to protect cornea epithelial cells. ${ }^{33}$ What is more, LC can reduce the decline of antioxidant enzymes to block apoptosis of cells causing by oxygen radicals. $^{34}$

The conjunctival goblet cells can synthesize and secrete mucin which can lubricate and protect the ocular surface. $^{35,36}$ The density of goblet cells is an important indicator of the health of the ocular surface. By calculating the density of goblet cells in the conjunctiva, the severity of DED can be assessed indirectly. ${ }^{37,38}$ Hypertonicity can lead to a decrease of goblet cells, resulting in insufficient ocular surface mucin secretion and instability of the tear film, leading to the occurrence and development of DED. ${ }^{39}$ At the same time, DED can promote squamous metaplasia of conjunctival epithelial cells which aggravates the damage of conjunctival goblet cells and decrease mucin secretion so that makes the condition worse. ${ }^{40}$ In our study, LCTG can significantly increase the number of conjunctival goblet cells which indicates its protective effect to the ocular surface.

In conclusion, as a new drug delivery system, LCTG shows better medicinal effect, overcomes the short retention time and low bioavailability of LCS. This study can lay the foundation for new ophthalmic preparations of LC.

\section{Conclusions}

Draize eye irritation test, corneal FLS staining examination, corneal histopathology examination and central corneal epithelial layer thickness measurement evaluated the 
irritation of rabbits with multiple administrations of LCTG. The results showed that LCTG has good biocompatibility, no obvious irritation to rabbit eyes, meeting the safety requirements of ophthalmic preparations. The tear secretion test, corneal fluorescein staining examination, corneal and lacrimal gland HE staining, corneal TUNEL staining and immunofluorescence staining, and conjunctival PAS staining were used to evaluate the effects of LCS and LCTG on DED model mice induced by ammonium chloride solution from four aspects (tear film, cornea, lacrimal gland and conjunctiva). The results show that LCTG can significantly increase the amount of tear secretion and the number of conjunctival goblet cells, improve the degree of corneal damage and the pathological morphology of the lacrimal gland and down-regulate the apoptosis rate of corneal epithelial cells as well as the expression level of MMP-3 and MMP-9. And the overall curative effect is better than LCS, indicating that the designed temperature-sensitive insitu gel delivery system can better exert the curative effect of LC in the treatment of DED compared with the traditional eye drops formulation.

\section{Institutional Review Board Statement}

The study was conducted following the statement for the Use of Animals in Ophthalmic and Vision Research, and approved by the Institutional Animal Ethics Committee of Beijing University of Chinese Medicine (protocol code BUCM-4-2019112602-4068). All authors have read NC3Rs ARRIVE guidelines carefully before the research.

\section{Funding}

This research was supported by Beijing Natural Science Foundation (7202123).

\section{Disclosure}

The authors declare no potential conflicts of interest for this work.

\section{References}

1. Holland EJ, Mannis MJ, Lee WB. Ocular surface disease: cornea, conjunctiva and tear film: expert consult-online and print. Elsevier Health Sci. 2013.

2. Liu NN, Liu L, Li J, Sun YZ. Prevalence of and risk factors for dry eye symptom in mainland China: a systematic review and meta-analysis. $J$ Ophthalmol. 2014;2014:2014. doi:10.1155/2014/ 748654

3. Craig JP, Nichols KK, Akpek EK, et al. TFOS DEWS II definition and classification report. Ocul Surf. 2017;15(3):276-283. doi:10.1016/j. jtos.2017.05.008
4. Gayton JL. Etiology, prevalence, and treatment of dry eye disease. Clin Ophthalmol. 2009;3(1):405-412. doi:10.2147/OPTH.S5555

5. Johnson ME, Murphy PJ. Changes in the tear film and ocular surface from dry eye syndrome. Prog Retin Eye Res. 2004;23(4):449-474.

6. Stapleton F, Alves M, Bunya VY, et al. Tfos dews ii epidemiology report. Ocul Surf. 2017;15(3):334-365.

7. Bron AJ, de Paiva CS, Chauhan SK, et al. Tfos dews ii pathophysiology report. Ocul Surf. 2017;15(3):438-510.

8. Jones L, Downie LE, Korb D, et al. TFOS DEWS II management and therapy report. Ocul Surf. 2017;15(3):575-628.

9. Khajavi N, Reinach PS, Skrzypski M, Lude A, Mergler S. L-carnitine reduces in human conjunctival epithelial cells hypertonic-induced shrinkage through interacting with TRPV1 channels. Cell Physiol Biochem. 2014;34(3):790-803. doi:10.1159/000363043

10. Hua X, Su Z, Deng R, Lin J, Li DQ, Pflugfelder SC. Effects of L-carnitine, erythritol and betaine on pro-inflammatory markers in primary human corneal epithelial cells exposed to hyperosmotic stress. Curr Eye Res. 2015;40(7):657-667. doi:10.3109/02713683.2014.957776

11. Huo J, Xie HP, Li J, Zhou D. A primary study of L-carnitine protective effect on corneal and conjunctival epithelium of mouse dry eye model induced by hyperosmolar saline. Chin J Opthalmol. 2012;48(4):330.

12. Bhattacharjee A, Das PJ, Adhikari P, et al. Novel drug delivery systems for ocular therapy: with special reference to liposomal ocular delivery. Eur $J$ Ophthalmol. 2019;29(1):113-126. doi:10.1177/ 1120672118769776

13. Choi SW, Kim J. Therapeutic contact lenses with polymeric vehicles for ocular drug delivery: a review. Materials. 2018;11(7):1125. doi:10.3390/ma11071125

14. Patel A, Cholkar K, Agrahari V, Mitra AK. Ocular drug delivery systems: an overview. World $J$ Pharmacol. 2013;2(2):47-64. doi:10.5497/wjp.v2.i2.47

15. Nguyen DD, Lai JY. Advancing the stimuli response of polymer-based drug delivery systems for ocular disease treatment. Polym Chem. 2020;11(44):6988-7008. doi:10.1039/D0PY00919A

16. Wu Y, Liu Y, Li X, et al. Research progress of in-situ gelling ophthalmic drug delivery system. Asian J Pharm Sci. 2019;14 (1):1-15. doi:10.1016/j.ajps.2018.04.008

17. Yadav KS, Rajpurohit R, Sharma S. Glaucoma: current treatment and impact of advanced drug delivery systems. Life Sci. 2019;21:362-376. doi:10.1016/j.lfs.2019.02.029

18. Lai JY, Luo LJ, Nguyen DD. Multifunctional glutathione-dependent hydrogel eye drops with enhanced drug bioavailability for glaucoma therapy. Chem Eng J. 2020;402:126190. doi:10.1016/j.cej.2020.126190

19. Pengcheng T, Jun W. Preparation and ocular retention of aciclovir chitosan eye-drops. J Guangdong Pharm Univ. 2013;29(3):225-228.

20. Nan L. Study of diclofenac temperature sensitive hydrogel with bioadhesive eye. Chin J Med Guide. 2015;17(02):177-179.

21. Li YJ, Luo LJ, Harroun SG, et al. Synergistically dual-functional nano eye-drops for simultaneous anti-inflammatory and anti-oxidative treatment of dry eye disease. Nanoscale. 2019;11 (12):5580-5594. doi:10.1039/C9NR00376B

22. Luo LJ, Nguyen DD, Lai JY. Long-acting mucoadhesive thermogels for improving topical treatments of dry eye disease. Mater Sci Eng C. 2020;15:111095. doi:10.1016/j.msec.2020.111095

23. Luo LJ, Lai JY. Epigallocatechin gallate-loaded gelatin-g-poly (N-isopropylacrylamide) as a new ophthalmic pharmaceutical formulation for topical use in the treatment of dry eye syndrome. Sci Rep. 2017;7(1):1-14. doi:10.1038/s41598-016-0028-x

24. Chen W, Zhang X, Li J, et al. Efficacy of osmoprotectants on prevention and treatment of murine dry eye. Invest Ophthalmol Vis Sci. 2013;54(9):6287-6297. doi:10.1167/iovs.13-12081

25. Acar D, Molina-Martínez IT, Gómez-Ballesteros M, Guzmán-Navarro M, Benítez-del-Castillo JM, Herrero-Vanrell R. Novel liposome-based and in situ gelling artificial tear formulation for dry eye disease treatment. Cont Lens Anterior Eye. 2018;41(1):93-96. doi:10.1016/j. clae.2017.11.004 
26. Kwon S, Kim SH, Khang D, Lee JY. Potential therapeutic usage of nanomedicine for glaucoma treatment. Int $J$ Nanomedicine. 2020;5:5745. doi:10.2147/IJN.S254792

27. Hiratani H, Fujiwara A, Tamiya Y, Mizutani Y, Alvarez-Lorenzo C. Ocular release of timolol from molecularly imprinted soft contact lenses. Biomaterials. 2005;26(11):1293-1298. doi:10.1016/j. biomaterials.2004.04.030

28. Camillieri G, Bucolo C, Rossi S, Drago F. Hyaluronan-induced stimulation of corneal wound healing is a pure pharmacological effect. $J$ Ocul Pharmacol Th. 2004;20(6):548-553. doi:10.1089/jop.2004.20.548

29. Gomes J, Amankwah R, Powell-Richards A, Dua H. Sodium hyaluronate (hyaluronic acid) promotes migration of human corneal epithelial cells in vitro. Briti $J$ Ophthalmol. 2004;88(6):821-825. doi:10.1136/bjo.2003.027573

30. Dicker KT, Gurski LA, Pradhan-Bhatt S, Witt RL, Farach-Carson MC, Jia X. Hyaluronan: a simple polysaccharide with diverse biological functions. Acta Biomater. 2014;10(4):1558-1570.

31. Thomas L. Analysis of draize eye irritation testing and its prediction by mining publicly available 2008-2014 REACH data. Altex. 2016;33(2):123-134. doi:10.14573/altex.1510053

32. Chen W, Zhang X, Liu M, et al. Trehalose protects against ocular surface disorders in experimental murine dry eye through suppression of apoptosis. Exp Eye Res. 2009;89(3):311-318. doi:10.1016/j. exer.2009.03.015

33. Deng $\mathrm{R}, \mathrm{Su} Z$, Hua $\mathrm{X}$, Zhang Z, Li DQ, Pflugfelder SC. Osmoprotectants suppress the production and activity of matrix metalloproteinases induced by hyperosmolarity in primary human corneal epithelial cells. Mol Vis. 2014;20(2):1243.
34. Hua X, Deng R, Li J, et al. Protective effects of L-carnitine against oxidative injury by hyperosmolarity in human corneal epithelial cells. Invest Ophthalmol Vis Sci. 2015;56(9):5503-5511. doi:10.1167/ iovs.14-16247

35. Inatomi T, Spurr-Michaud S, Tisdale AS, Zhan Q, Feldman ST, Gipson IK. Expression of secretory mucin genes by human conjunctival epithelia. Invest Ophthalmol Vis Sci. 1996;37(8):1684-1692.

36. Paulsen FP, Berry MS. Mucins and TFF peptides of the tear film and lacrimal apparatus. Prog Histochem Cytochem. 2006;41(1):1-53.

37. Argüeso P, Guzman-Aranguez A, Mantelli F, Cao Z, Ricciuto J, Panjwani N. Association of cell surface mucins with galectin-3 contributes to the ocular surface epithelial barrier. J Biol Chem. 2009;284 (34):23037-23045. doi:10.1074/jbc.M109.033332

38. YañEz-Soto B, Mannis MJ, Schwab IR, et al. Interfacial phenomena and the ocular surface. Ocul Surf. 2014;12(3):178-201.

39. Baudouin C, Rolando M, Del Castillo JMB, et al. Reconsidering the central role of mucins in dry eye and ocular surface diseases. Prog Retin Eye Res. 2019;1:68-87.

40. Lemp MA. The mucin-deficient dry eye. Int Ophthalmol Clin. 1973;13(1):185-189. doi:10.1097/00004397-197301310-00013
Drug Design, Development and Therapy

\section{Publish your work in this journal}

Drug Design, Development and Therapy is an international, peerreviewed open-access journal that spans the spectrum of drug design and development through to clinical applications. Clinical outcomes, patient safety, and programs for the development and effective, safe, and sustained use of medicines are a feature of the journal, which has also

\section{Dovepress}

been accepted for indexing on PubMed Central. The manuscript management system is completely online and includes a very quick and fair peer-review system, which is all easy to use. Visit http://www. dovepress.com/testimonials.php to read real quotes from published authors. 